\title{
Review
}

\section{Emerging roles of caspase-3 in apoptosis}

\author{
Alan G. Porter ${ }^{\star, 1}$ and Reiner U. Jänicke ${ }^{1}$ \\ 1 Institute of Molecular and Cell Biology, The National University of Singapore, \\ 30 Medical Drive, Singapore 117609, Republic of Singapore \\ * corresponding author: Alan G. Porter, Institute of Molecular and Cell Biology, \\ The National University of Singapore, 30 Medical Drive, Singapore 117609, \\ Republic of Singapore; tel: 65 874-3761; fax: 65 779-1117; \\ email: mcbagp@imcb.nus.edu.sg
}

Received 23.9.98; revised 5.11.98; accepted 12.11 .98 Edited by G. Salvesen

\begin{abstract}
Caspases are crucial mediators of programmed cell death (apoptosis). Among them, caspase-3 is a frequently activated death protease, catalyzing the specific cleavage of many key cellular proteins. However, the specific requirements of this (or any other) caspase in apoptosis have remained largely unknown until now. Pathways to caspase-3 activation have been identified that are either dependent on or independent of mitochondrial cytochrome $c$ release and caspase-9 function. Caspase- 3 is essential for normal brain development and is important or essential in other apoptotic scenarios in a remarkable tissue-, cell type- or death stimulus-specific manner. Caspase-3 is also required for some typical hallmarks of apoptosis, and is indispensable for apoptotic chromatin condensation and DNA fragmentation in all cell types examined. Thus, caspase- 3 is essential for certain processes associated with the dismantling of the cell and the formation of apoptotic bodies, but it may also function before or at the stage when commitment to loss of cell viability is made.
\end{abstract}

Keywords: caspase-3; cytochrome c; apoptotic morphology; DNA fragmentation

Abbreviations: ICE, interleukin $1 \beta$-converting enzyme; ES cell, embryonic stem cell; PARP, poly(ADP-ribose) polymerase; PAK2, p21-activated kinase 2; ICAD/DFF-45, inhibitor of caspaseactivated DNase/DNA fragmentation factor-45; CAD, caspaseactivated DNase; PT, (mitochondrial) permeability transition; Apaf1 , apoptosis-activating factor 1

\section{Introduction}

Apoptosis is a fundamental and complex biological process that enables an organism to kill and remove unwanted cells during animal development, normal homeostasis and disease. $^{1,2}$ Of all the proteins implicated in the activation and execution of apoptosis, the ICE-like proteases or caspases (14 so far identified in humans) stand out as being crucial for this process in diverse metazoan organisms. $^{3-5}$ In mammals, caspases (principally caspase-3) appear to be activated in a protease cascade that leads to inappropriate activation or rapid disablement of key structural proteins and important signaling, homeostatic and repair enzymes. ${ }^{3}$ Caspase- 3 is a frequently activated death protease; however, the specific requirements of this (or any other) caspase in apoptosis were until now largely unknown. Recent work, reviewed here, has revealed that caspase-3 is important for cell death in a remarkable tissue-, cell type- or death stimulus-specific manner, and is essential for some of the characteristic changes in cell morphology and certain biochemical events associated with the execution and completion of apoptosis.

\section{Caspase- 3 is a frequently activated protease in mammalian cell apoptosis}

It is clear that multiple pathways to apoptosis exist that originate from a variety of cell surface receptor-triggered or other events. ${ }^{3,6}$ Although there are at least 14 caspases in humans, ${ }^{4,7}$ only a subset of these enzymes is detectably proteolytically activated by various distinct death stimuli in different cell types. ${ }^{8-10}$ However, pro-caspase-3 is usually present and processed by autoproteolytic cleavage (or cleavage by one or more other proteases in trans) that leads to assembly of the active heterotetrameric enzyme. ${ }^{8-10}$ The frequent activation of caspase- 3 in different cell types raises the fundamental question of whether this protease is required for the death of the cell and for the many morphological changes associated with apoptosis. Unfortunately, there is one other known caspase-3-like protease in vertebrates (caspase 7) with an analogous in vitro substrate preference to caspase-3 [DEVDG, where cleavage occurs between the aspartic acid (D) and the glycine (G)]. ${ }^{3,11}$ Moreover, the existence of other caspase-3-like proteases cannot be ruled out. Therefore, the activation of caspase- 3 is not by itself proof that it is required for apoptotic events and cell death.

\section{Caspase-3 is required for some, but not all, cell deaths and distinct apoptotic processes}

Caspase-3 is important for survival, as caspase-3-knockout mice are born at a low frequency and die after only a few weeks. ${ }^{12,13}$ These mice have a striking phenotype in which there are skull defects with ectopic masses of supernumerary cells that represent the failure of programmed cell death during development in the brain, but not, surprisingly, in other organs or tissues. Thus, caspase- 3 acts in a tissue selective manner, and there are at least two possible explanations for it. There may be a shortage of crucial caspase-3-like proteases that can substitute for caspase-3 at a critical stage in the 
neural apoptosis programme, or caspase- 3 may lie at the heart of an essential neural death pathway.

Consistent with the lack of any obvious morphological defects in tissues or organs other than the brain, immature $T$ and $B$ cells from these mice undergo apoptosis normally. ${ }^{12,13}$ In contrast, caspase-3-defective peripheral $\mathrm{T}$ cells are less susceptible to $\mathrm{CD} 3 \varepsilon^{-}$and Fas receptorinduced apoptosis and activation-induced cell death than similar cells from wild-type mice. ${ }^{13}$ This indicates that caspase-3 contributes to apoptosis in peripheral T cells, but is dispensable during $\mathrm{T}$ and $\mathrm{B}$ cell differentiation. Remarkably, caspase-3-defective embryonic stem (ES) cells are highly resistant to apoptosis induced by UVirradiation and osmotic shock, but are as sensitive to $\gamma$ irradiation and heat shocks as ES cells from wild-type mice. ${ }^{13}$ In the absence of caspase-3, bone marrow neutrophils are slightly more resistant to cycloheximideinduced apoptosis; and caspase-3-defective mouse fibroblasts transformed with the adenovirus E1A gene and the activated $\mathrm{p} 21^{\text {ras }}$ oncogene exhibit reduced and delayed cell death, which is completely restored by introducing the wildtype CASP-3 gene. ${ }^{13}$ Thus, caspase-3 makes an essential contribution to cell death in some, but not all, scenarios in a remarkable tissue-, cell type- or death stimulus-specific manner. In contrast, all cell types examined from caspase3-defective mice fail to display some typical hallmarks of apoptosis (extensive chromatin condensation and DNA fragmentation) following treatment with various death stimuli, whereas externalization of phosphatidylserine still occurs. $^{13}$

Similar results were independently obtained with the human MCF-7 breast carcinoma cell line in which the $C A S P-3$ gene is functionally deleted due to a genomic mutation, introducing a premature stop codon in the mRNA. ${ }^{14}$ It is known that MCF-7 cells are killed by various inducers of apoptosis in the complete absence of DNA strand breakage and without many of the characteristic morphological changes. ${ }^{15}$ The absence of caspase-3 in this cell line explains why, since introduction of CASP-3 cDNA restores DNA fragmentation and membrane blebbing of MCF-7 cells undergoing apoptosis. ${ }^{14}$ In a different approach, a selective inhibitor of caspase-3-like proteases was shown to block caspase-3 activation. DNA fragmentation and chromatin condensation in Jurkat $T$ cells, and it was concluded that caspase-3 plays a central role in mediating nuclear apoptosis. ${ }^{16}$ Together these results demonstrate that in multiple cell types, caspase-3 is required for some typical nuclear and other morphological changes associated with the completion of apoptosis and the formation of apoptotic bodies (Figure 1). ${ }^{13,14,16}$ These findings also show that loss of cell viability caused by various inducers of apoptosis can still occur without chromatin condensation, DNA fragmentation and membrane blebbing (Figure 1).

What are the actual caspase-3-dependent steps that mediate the nuclear and other morphological changes of apoptosis? At least 42 of the 58 known caspase substrates are specifically cleaved by caspase-3 or a related protease, and caspase- 3 can process pro-caspases 2, 6, 7 and 9, further illustrating the extensive involvement of caspase-3 or related proteases in cell death. ${ }^{3,4}$ TNF- or staurosporineinduced apoptosis of caspase-3-defective MCF-7 cells still results in the cleavage of several death substrates known to be susceptible to caspase-3, including poly(ADP-ribose) polymerase (PARP), the retinoblastoma protein and the DNA-dependent protein kinase catalytic subunit. ${ }^{17}$ In contrast, the caspase-dependent cleavage of the actinbinding protein $\alpha$-fodrin ${ }^{18}$ into the typical $120-k D a$ fragment does not occur. Introduction of CASP-3 cDNA into MCF-7 cells restores $\alpha$-fodrin cleavage as well as membrane blebbing. ${ }^{14,17}$ These results indicate that caspase-3 is essential for $\alpha$-fodrin cleavage in MCF-7 cells, but dispensable for the cleavage of several other death substrates, and suggest that $\alpha$-fodrin cleavage may contribute to blebbing (Figure 1 ). Proteolysis of $\alpha$-fodrin had earlier been suggested to contribute to the structural rearrangements including blebbing during apoptosis. ${ }^{19}$ This is supported by the fact that fodrin (a major component of the cortical cytoskeleton of most eukaryotic cells) has binding sites for microtubules, calmodulin and actin. ${ }^{17}$ However, since $\alpha$-fodrin is also cleaved by calpain in a caspase-independent fashion, ${ }^{18}$ further studies are needed to assess the specific function of the caspase-mediated cleavage of $\alpha$-fodrin in the disassembly of the cell.

Evidence was presented that the caspase-3-mediated cleavages of PAK2 and gelsolin lead to the morphological changes associated with apoptosis. ${ }^{20,21}$ In the case of gelsolin, caspase-3 generates a fragment that severs actin filaments in an unregulated fashion. ${ }^{20}$ The cleavage of gelsolin is an important event in apoptosis, because the enforced expression of the gelsolin fragment in several cells causes them to round up, detach and undergo nuclear fragmentation. In addition, TNF- and cycloheximide-treated neutrophils isolated from gelsolin-deficient mutant mice have an extremely delayed onset of membrane blebbing compared with wild-type neutrophils. ${ }^{20}$ As caspase-3 is essential for gelsolin cleavage, ${ }^{22}$ these results show that membrane blebbing is mediated, at least in part, by the activation of gelsolin by caspase-3.

ICAD/DFF-45 is a binding partner and inhibitor of the CAD endonuclease, and the specific cleavage of ICAD/ DFF-45 by caspase-3 relieves the inhibition and promotes the endonuclease activity of CAD, resulting in apoptotic DNA fragmentation. ${ }^{23-25}$ Caspase-3 is required for the carboxy-terminal cleavage of ICAD/DFF-45 that is necessary for the generation of the functional endonuclease. ${ }^{22}$ Since DNA fragmentation is largely absent in apoptotic cells from mutant mice lacking ICAD/DFF $-45^{26}$ and is not detected in cells lacking caspase- $3,{ }^{13,14}$ the cleavage of ICAD/DFF-45 resulting in the induction of the CAD endonuclease is a caspase-3-dependent step in a major pathway to DNA fragmentation in apoptosis.

These considerations raise a fundamental question. Is caspase-3 indispensable for cell death and/or morphological changes in certain cell types, or is it required only because other caspases are not expressed or activated, which could otherwise fulfill the function of caspase-3? We cannot, unfortunately, distinguish between these possibilities, because many investigators have only been able to detect the activation of a subset of caspases in various 
cell types, and rarely is the activation of all known caspases measured. $^{8-10}$ In MCF-7 cells there is no detectable activation of caspase 7 , which has an in vitro substrate specificity similar to that of caspase-3, leaving open the possibility that if it were activated, caspase 7 might be able to fulfill the function of caspase- 3 in $\alpha$-fodrin, gelsolin and ICAD/DFF-45 cleavage in these cells. ${ }^{17}$ Similarly, it is worth considering that the remarkable celland tissue-selective requirement for caspase-3 in the CASP-3 ${ }^{-1-}$ mutant mice and cell lines may be explained, at least in part, by the absence of activated proteases that can substitute for caspase-3 in specific cell types (e.g. in the brain).

\section{Significance of cell death without morphological changes and DNA fragmentation}

Surprisingly, mutant mice with a non-functional ICAD/DFF-45 gene are healthy with no obvious abnormalities. ${ }^{26}$ In contrast to cells from wild-type mice, cells from these mutant animals exposed to apoptotic stimuli exhibit almost no DNA fragmentation, and chromatin condensation is severely impaired. These findings strongly imply that DNA degradation and perhaps also chromatin condensation are dispensable for in vivo programmed cell death during development of all tissues and organs, including the brain. ${ }^{26}$

\section{ROLES OF CASPASE-3 IN APOPTOSIS}

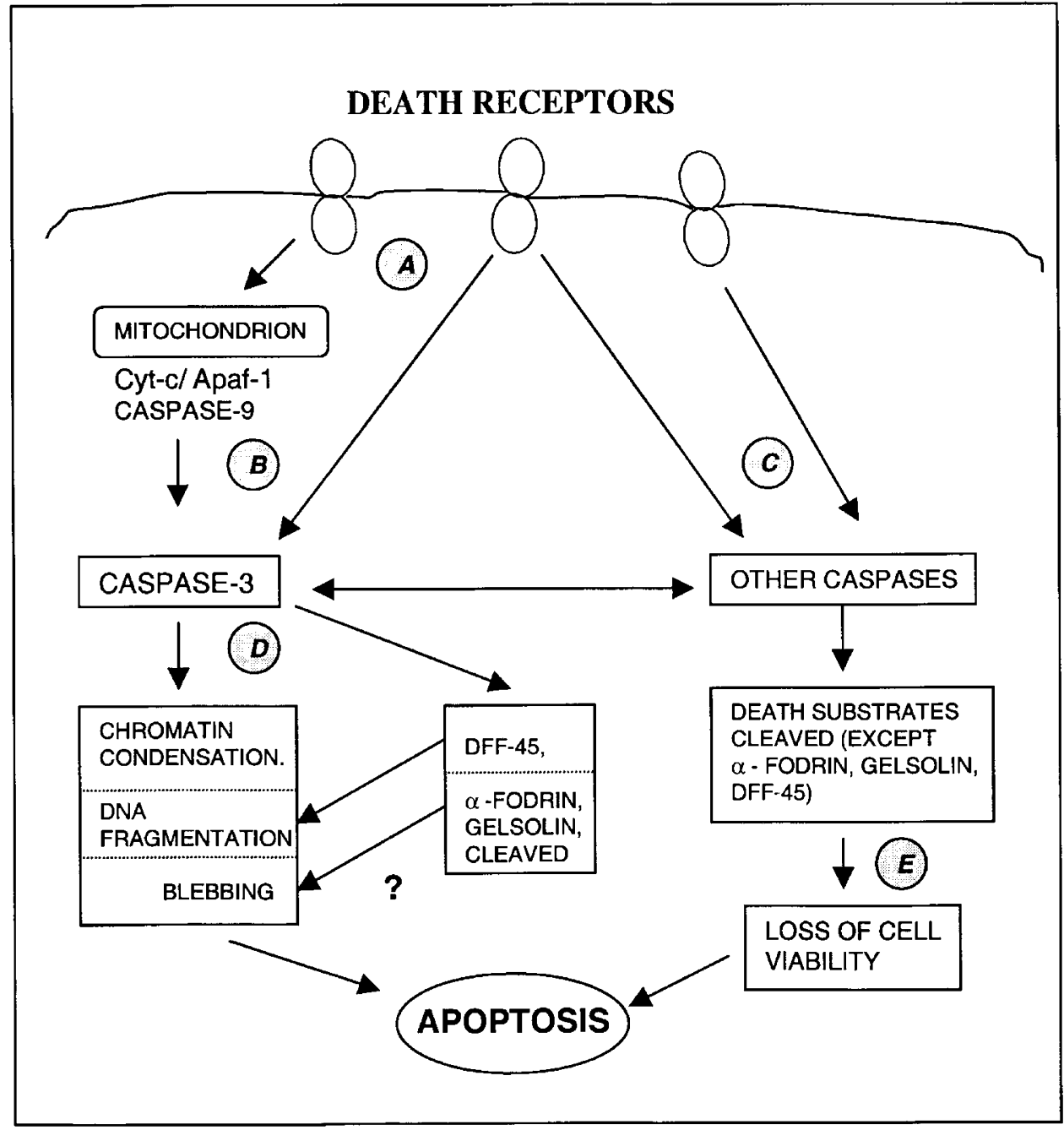

Figure 1 Involvement of caspase-3 in apoptosis pathways. The salient points are: (1) Pathways to caspase-3 activation may be dependent on ${ }^{6,29,31,32}$ or independent of 6,34 mitochondrial cytochrome $c$ release (marked A, B). (2) Caspase-3 activation may be dependent on or independent of caspase-9 (marked $\mathbf{A}$, B). ${ }^{36,37}$ (3) Cell death pathways exist that are either dependent on (marked A, B) or independent of caspase-3 (marked C). ${ }^{12-14,17,27,31}$ (4) Caspase-3 is required for $\alpha$-fodrin, DFF-45 and gelsolin cleavage (MCF-7 cells), blebbing (MCF-7 cells), and chromatin condensation and DNA fragmentation (marked D). ${ }^{13,14,17,22,23}$ (5) $\alpha$-fodrin, DFF-45 and gelsolin cleavage by caspase-3, as well as chromatin condensation, DNA fragmentation and blebbing are not essential for loss of cell viability $(\text { marked } \mathbf{E})^{13-15,17,22}$ 
As discussed above, distinct caspase-3-deficient cell types are efficiently killed by apoptosis inducers without blebbing, DNA fragmentation and proper chromatin condensation; ${ }^{13-15}$ yet other classic apoptotic events occur, including activation of caspases and specific cleavage of some death substrates. In other words, the death of cells from caspase-3-knockout mice and MCF-7 cell death appears to occur via an incomplete form of apoptosis. ${ }^{13-15}$ Cellular disintegration is unnecessary for the apoptotic death of cultured cell monolayers, because the dying cells simply detach from the plastic surface. In contrast, it has been assumed up till now that dying cells in the whole organism must shrink and be fragmented into discreet bodies that can be conveniently and rapidly engulfed by phagocytic cells. ${ }^{2}$ Moreover, it has been pointed out that intact naked DNA is 'dangerous stuff', as it could potentially colonize and scramble the genomes of neighboring cells. ${ }^{25}$ The apparently normal programmed cell death during development in the ICAD/DFF-45deficient mice ${ }^{26}$ and in the caspase-3-knockout mice in tissues and organs other than the brain ${ }^{12,13}$ is, therefore, puzzling as it implies that cell death and the removal of the corpse in vivo occurs without the need for many of the processes that up till now have been considered an integral part of apoptosis.

\section{The cytochrome c - caspase-3 connection}

There is considerable evidence that disruption of mitochondrial functions (e.g. loss of transmembrane potential, permeability transition (PT) and release of cytochrome $c$ leading to impaired electron transport) are important events in many apoptotic cell deaths (Figure 1). ${ }^{27-30}$ The release of cytochrome $\mathrm{c}$ induced by a variety of death stimuli results in the activation of a complex of apoptosis-activating factor 1 (Apaf-1) and caspase-9, leading to the cytochrome cdependent processing of pro-caspase-3 and apoptosis in a number of scenarios (Figure 1). ${ }^{27,28,30-32}$

Microinjected cytochrome c causes apoptosis of HeLa carcinoma and embryonic kidney 293 cells, but not of caspase-3-defective MCF-7 cells. ${ }^{33}$ Transformation of MCF-7 cells with CASP-3 cDNA restores cytochrome c sensitivity, demonstrating that cytochrome c-mediated apoptosis requires caspase- $3 .^{33}$ There is evidence that caspase-3 activation can also occur independently of mitochondrial cytochrome c release. ${ }^{6,34}$ For example, two cell type-dependent death pathways emanating from the Fas receptor have been discovered. ${ }^{6}$ In type II cells, apoptotic cell death was inhibited by $\mathrm{Bcl}-2$ and depended on the loss of mitochondrial functions; whereas in type I cells, apoptosis (involving caspase-3 activation) was not blocked by $\mathrm{Bcl}-2$ even though $\mathrm{Bcl}-2$ prevented disruption of mitochondrial functions including cytochrome c release. ${ }^{6}$ In multiple myeloma cells, there exist cytochrome c-dependent and -independent mechanisms of apoptosis, both of which involve caspase- 3 activation. ${ }^{34}$

Once caspase-3 is activated, downstream death substrates are cleaved irrespective of the involvement of cytochrome c. ${ }^{3,4,28}$ But caspase-3 might also amplify the upstream death cascade, including cytochrome $c$ release from mitochondria, by cleaving Bcl-2, converting it from an anti-apoptotic to a pro-apoptotic protein. ${ }^{35}$ Together these results indicate that mitochondria certainly play a role in apoptosis, but also mean that in some situations caspase-3 is activated when the mitochondrial step is completely bypassed. Furthermore, the release of cytochrome c can theoretically occur downstream of caspase-3 in some instances, and apoptotic cell death does not always involve the cytochrome c-dependent activation of caspase-3.

Embryos from caspase-9-knockout mice show evidence of impaired brain development associated with decreased apoptosis that is highly reminiscent of $C A S P-3^{-1-}$ mutant mice. $^{36,37}$ In the embryonic brains of $C A S P-9^{-1-}$ mutant mice, the absence of caspase- 9 prevents the activation of caspase-3; and the cytochrome c-dependent processing of pro-caspase-3 fails to occur in cytosolic extracts of caspase9-deficient thymocytes and embryonic brain cells, but is restored after the addition of caspase- $9 .{ }^{37}$ Thus, caspase- 9 is confirmed as a critical upstream activator of caspase-3 (Figure 1). There appear to be at least two classes of caspase-9-dependent pathways, only one of which requires caspase-3. ${ }^{36,37}$ For example, caspase-9-dependent death of embryonic stem (ES) cells requires caspase- 3 activation, whereas the caspase-9-dependent death of thymocytes induced by dexamethasone or $\gamma$-radiation does not. The picture is even more complicated because caspase- 9 is not always an obligatory upstream activator of caspase- 3 (Figure 1). Thus, caspase-9 deficiency does not protect activated $T$ cells from apoptosis induced by $\alpha$-CD95 (via Fas) or $\alpha$-CD3 and does not prevent caspase-3 activation in response to these stimuli in vivo. ${ }^{36}$ This latter caspase-9independent pathway is reminiscent of the Fas-induced, Bcl2-independent pathway to caspase-3 activation in type I cells mentioned above. ${ }^{6}$

Curiously, the introduction of some pro-apoptotic proteins into cells causes death independently of caspases. Enforced expression of pro-apoptotic members of the Bcl-2 family (e.g. Bax) kills mammalian cells, accompanied by membrane alterations and DNA condensation, but without DNA fragmentation and caspase activation. $^{38-40}$ These studies on the expression of Baxlike proteins are consistent with the conclusion that DNA fragmentation requires functional caspase-3 and, importantly, imply that not all morphological changes in dying cells require caspases. The fact that Bax can cause cytochrome $c$ release ${ }^{41}$ and promote mitochondrial PT or puncture the mitochondrion in a caspase-independent fashion $^{40}$ further emphasizes the importance of the disruption of mitochondrial functions in apoptosis.

\section{Conclusions}

Caspase-3 is probably the best understood of the mammalian caspases in terms of its specificity and roles in apoptosis (summarized in Figure 1). Overall, recent progress has generally confirmed the notion of multiple, complex death pathways (some of which require caspase- 3 in specific cell types) that converge on common events including cell shrinkage, blebbing, chromatin condensation and DNA 
fragmentation (which appear to require caspase-3 in all cell types so far examined) (Figure 1). The main message is that caspase-3 can exert multiple effects. Some of these effects are critical for cell death to occur, but only in specific cell types treated with some death inducers. Other effects of caspase-3 (certain morphological and nuclear changes resulting, at least in part, from the caspase-3-mediated cleavages of $\alpha$-fodrin, gelsolin and ICAD/DFF-45) may ensure the efficient completion of the apoptotic process once the cell has been committed to die.

In the future, we must try to understand the molecular basis of the selective requirement for caspase- 3 in neural development and in certain cell types induced to die with particular extracellular stimuli. ${ }^{12,13}$ In other words, exactly which caspase-3-dependent proteolytic events are required to cause these cells to die? Some of the answers will emerge with the discovery of new caspase-3 substrates; others will come from measuring the activation spectrum of known caspases in a range of caspase-3-deficient cells, and determining which (if any) of these caspases can substitute for caspase-3 (and which cannot). Another intriguing question is whether programmed cell death in the caspase-3- and ICAD/DFF-45-knockout mice really does occur without many of the morphological and nuclear changes that have been assumed to lead to the phagocytosis of apoptotic bodies.

\section{Acknowledgements}

We thank M. Choi and M.L. Sprengart for critically reading the manuscript. This work was supported by the Institute of Molecular and Cell Biology, Singapore.

\section{References}

1. Thompson CB (1995) Apoptosis in the pathogenesis and treatment of disease. Science 267: $1456-1462$

2. Jacobson MD, Weil M and Raff MC (1997) Programmed cell death in animal development. Cell 88: 347-354

3. Nicholson DW and Thornberry A (1997) Caspases: killer proteases. Trends Biochem. Sci. 22: 299-306

4. Cryns V and Yuan J (1998) Proteases to die for. Genes Dev. 12: 1551-1570

5. Thornberry NA and Lazebnik Y (1998) Caspases: enemies within. Science 281: 1312-1316

6. Scaffidi C, Fuldar S, Srinivasan A, Friesen C, Li F, Tomaselli KJ, Debatin K-M, Krammer PH and Peter ME (1998) Two CD95 (APO-1/Fas) signaling pathways. EMBO J. 17: 1675-1687

7. Van de Craen M, Van Loo G, Pype S, Van Criekenge W, Van den brande, Molemans F, Fiers W, Declercq W and Vandenabeele P (1998) Identification of a new caspase homologue: caspase-14. Cell Death Differ. 5: 838-846

8. Faleiro L, Kobayashi R, Fearnhead H and Lazebnik Y (1997) Multiple species of CPP32 and Mch2 are the major active caspases present in apoptotic cells. EMBO J. 16: $2271-2281$

9. Martins LM, Kottke T, Mesner PW, Basi GS, Sinha S, Frigon Jr N, Tatar E, Tung JS, Bryant K, Takahashi A, Svingen PA, Madden BJ, McCormick DJ, Earnshaw WC and Kaufmann SH (1997) Activation of multiple interleukin $1 \beta$-converting enzyme homologues in cytosol and nuclei of HL-60 cells during etoposideinduced apoptosis. J. Biol. Chem. 272: 7421-7430

10. Polverino AJ and Patterson SD (1997) Selective activation of caspases during apoptotic induction in HL-60 cells. J. Biol. Chem. 272: 7013-7021

11. Talanian RV, Quinlan C, Trautz S, Hackett MC, Mankovich JA, Banach D, Ghayur T, Brady KD and Wong WW (1997) Substrate specificities of caspase family proteases. J. Biol. Chem. 272: $9677-9682$
12. Kuida K, Zheng TS, Na S, Kuan C-Y, Yang D, Karasuyama H, Rakic P and Flavell RA (1996) Decreased apoptosis in the brain and premature lethality in CPP32deficient mice. Nature 384: 368-372

13. Woo M, Hakem R, Soengas MS, Duncan GS, Shahinian A, Kägi D, Hakem A, McCurrach M, Khoo W, Kaufman SA, Senaldi G, Howard T, Lowe SW and Mak TW (1998) Essential contribution of caspase-3/CPP32 to apoptosis and its associated nuclear changes. Genes Dev. 12: 806-819

14. Jänicke RU, Sprengart ML, Wati MR andPorter AG (1998) Caspase-3 is required for DNA fragmentation and morphological changes associated with apoptosis. J. Biol. Chem. 273: 9357-9360

15. OberhammerF, Wilson JW, Dive C, Morris ID, Hickman JA, Wakeling AE, Walker PR and Sikorska M (1993) Apoptotic death in epithelial cells: cleavage of DNA to 300 and/or $50 \mathrm{~kb}$ fragments prior to or in the absence of internucleosomal fragmentation. EMBO J. 12: 3679-3684

16. Hirata H, Takahashi A, Kobayashi S, Yonehara S, Sawai H, Okazaki T, Yamamoto K and Sasada M (1998) Caspases are activated in a branched protease cascade and control distinct downstream processes in Fas-induced apoptosis. J. Exp. Med. 187: 587-600

17. Jänicke RU, Ng P, Sprengart ML and Porter AG (1998) Caspase-3 is required for cleavage of $\alpha$-fodrin but dispensable for cleavage of other death substrates in apoptosis. J. Biol. Chem. 273: 15540-15545

18. Nath R, Raser KJ, Stafford D, Hajimohammedreza I, Posner A, Allen H, Talanian RV, Yuen P-W, Gilbertsen RB and Wang KKW (1998) Non-erythroid $\alpha$-spectrin breakdown by calpain and interleukin $1 \beta$-converting-enzyme-like protease(s) in apoptotic cells: contributory roles of both protease families in neuronal apoptosis. Biochem J. 319: 683-690

19. Martin SJ, O'Brien GA, Nishioka WK, McGahon AJ, Mahboubi A, Saido TC and Green DR (1995) Proteolysis of fodrin (non-erythroid spectrin) during apoptosis. J. Biol. Chem. 270: 6425-6428

20. Kothakota S, Azuma T, Reinhard C, Klippel A, Tang J, Chu K, McGarry TJ, Kirschner MW, Koths K, Kwiatkowski DJ and Williams LT (1997) Caspase-3generated fragment of gelsolin: effector of morphological change in apoptosis. Science 278: 294-298

21. Rudel T and Bokoch GM (1997) Membrane and morphological changes in apoptotic cells regulated by caspase-mediated activation of PAK2. Science 276 : $1571-1574$

22. Tang D and Kidd VJ (1998) Cleavage of DFF-45/ICAD by multiple caspases is essential for its function during apoptosis. J. Biol. Chem. 273: 28549-28552

23. Liu X, Zou H, Slaughter C and Wang (1997) DFF, a heterodimeric protein that functions downstream of caspase-3 to trigger DNA fragmentation during apoptosis. Cell 89: 175-184

24. Sakahira $H$, Enari $M$ and Nagata $S$ (1998) Cleavage of CAD inhibitor in CAD activation and DNA degradation during apoptosis. Nature 391: 96-99

25. Wyllie A (1998) An endonuclease at last. Nature 391: 20-21

26. Zhang J, Liu X, Scherer DC, Van Kaer L, Wang X and Xu M (1998) Resistance to DNA fragmentation and chromatin condensation in mice lacking the DNA fragmentation factor 45. Proc. Natl. Acad. Sci. USA 95: 12480-12485

27. Kluck RM, Martin SJ, Hoffman BM, Zho JS, Green DR and Newmeyer DD (1997) Cytochrome $\mathrm{c}$ activation of CPP32-like proteolysis plays a critical role in a Xenopus cell-free apoptosis system. EMBO J. 16: 4639-4649

28. Reed JC (1997) Cytochrome c: Can't live with it - can't live without it. Cell 91: $559-562$

29. Yang J, Liu X, Bhalla K, Kim CN, Ibardo AM, Cai J, Peng TI, Jones DP andWang X (1997) Prevention of apoptosis by Bcl-2: release of cytochrome c from mitochondria blocked. Science 275: 1129-1132

30. Zou H, Henzel WJ, Liu X, Lutschg A and Wang X (1997) Apaf-1, a human protein homologous to $\mathrm{C}$. elegans CED-4, participates in cytochrome c-dependent activation of caspase-3. Cell 90: 405-413

31. LiP, Nijhawan D, Budihardjo I, Srinivasula SM, Ahmad M, Alnemri ES and Wang $X$ (1997) Cytochrome $c$ and dATP-dependent formation of Apaf-1/caspase-9 complex initiates an apoptotic protease cascade. Cell 91: 479-489

32. Pan G, O'Rourke K and Dixit VM (1998) Caspase-9, Bcl-X , and Apaf-1 form a ternary complex. J. Biol. Chem. 273: 5841-5845

33. LiF, Srinivasan A, Wang Y, Armstrong RC, TomaselliKJ and Fritz LC (1997) Cellspecific induction of apoptosis by microinjection of cytochrome c. J. Biol. Chem. 272: 30299-30305

34. Chauhan D, Pandey P, Ogata A, Teoh G, Krett N, Halgren R, Rosen S, Kufe D, Kharbanda S and Anderson K (1997) Cytochrome c-dependent and independent induction of apoptosis in multiple myeloma cells. J. Biol. Chem. 272: $29995-29997$ 
35. Cheng EH-Y, Kirsch DG, Clem RJ, Ravi R, Kastan MB, Bedi A, Ueno K and Hardwick JM (1997) Conversion of Bcl-2 to a bax-like death effector by caspases. Sciences 278: 1966-1968

36. Hakem R, Hakem A, Duncan GS, Henderson JT, Woo M, Soengas MS, Elia A, de la Pompa JL, Kagi D, Khoo W, Potter J, Yoshida R, Kaufman SA, Lowe SW, Penninger JM and Mak TW (1998) Differential requirement for caspase-9 in apoptotic pathways in vivo. Cell 94: 339-352

37. Kuida K, Haydar TF, Kuan C-Y, GuY, Taya C, Karasuyama H, Su MS-S, Rakic P and Flavell RA (1998) Reduced apoptosis and cytochrome c-mediated caspase activation in mice lacking caspase 9. Cell 94: 325-337

38. Xiang J, Chao DT and Korsmeyer SJ (1996) BAX-induced cell death may not require interleukin 1 beta-converting enzyme-like proteases. Proc. Natl. Acad. Sci. USA 93: $14559-14563$
39. McCarthy NJ, Whyte MK, Gilbert CS and Evan GI (1997) Inhibition of Ced-3/ICErelated proteases does not prevent cell death induced by oncogenes, DNA damage, or the Bcl-2 homologue Bak. J. Cell Biol. 136: 215-227

40. Gross A, Jockel J, Wei MC and Korsmeyer SJ (1998) Enforced dimerization of $B A X$ results in its translocation, mitochondrial dysfunction and apoptosis. EMBO J. $17: 3878-3885$

41. Jürgensmeier JM, Xie Z, Deveraux Q, Ellerby L, Bredesen D and Reed J (1998) Bax directly induces release of cytochrome $\mathrm{c}$ from isolated mitochondria. Proc. Natl. Acad. Sci. USA 95: 4997-5002 